\title{
Construção de um bio-eléctrodo específico para determinação de nitritos
}

\author{
M. GABRIEA A L MEIDA, FEDRO TAVARES E JOSÉ J.G. MOURA*
}

A actividade experimental a seguir apresentada tem sido demonstrada como trabalho laboratorial da disciplina de Métodos Instrumentais de Análise II, do $3 .^{\circ}$ ano do Licenciatura em Química Aplicada leccionada no Departamento de Química da Faculdade de Ciências e Tecnologia, Universidade Nova de Lisboa. Este protocolo representa, por outro lado, uma transferência directa de conhecimento entre actividades de investigação fundamental em curso nos Grupos de Bioinorgânica e de Bioquímica e Biofísica de Proteínas do Centro de Química Fina e Biotecnologia e a leccionação curricular na secçẫo de Química-Física e Inorgânica. Portanto, a elaboração deste protocolo e sua realização experimental pelos alunos da licenciatura representa um estímulo para os discentes e um melhor conhecimento da actividade de investigação levada a cabo pelos docentes. A acentuada interdisciplinaridade deste trabaIho (introduzindo uma combinação de conceitos analíticos actuais como tecnologia de biosensores e noções importantes de electroquímica e de cinética enzimática) permite inclui-lo no curriculo de outras disciplinas, tais como Electroquimica ou Biotecnologia.

\section{Introdução}

Os sais de nitrito $\left(\mathrm{NO}_{2}^{-}\right)$e de nitrato $\left(\mathrm{NO}_{3}^{-}\right)$são aditivos correntemente usados na indústria alimentar, quer como agentes conservantes, quer para melhorar a côr e o sabor de alimentos processados. Os nitratos podem ainda ocorrer nos alimentos de origem vegetal e nas águas potáveis em consequência da sua ampla utilização como fertilizantes na agricultura. A exposiçāo do Homem a niveis importantes destes químicos pode ter implicações graves na saúde pública. A toxicidade advém essencialmente da acção do nitrito na conversão da hemoglobina em metahemoglobina, reduzindo consequentemente a capacidade do sangue transportar o oxigénio; esta situação é especialmente crítica nas crianças, em virtude do menor conteúdo em hemoglobina. A perigosidade do ião nitrito é amplificada pela sua reacção com aminas secundárias existentes nos alimentos, resultando na formação de compostos $\mathrm{N}$-nitroso cujos efeitos carcinogéneos são alvo de gran- de debate. Quanto ao ião nitrato, per se, é menos tóxico, mas é facilmente convertido em nitrito por certos microrganismos existentes nas águas e solos, bem como no próprio organismo humano [1-5].

Por outro lado, tanto os nitratos como os nitritos são metabolitos estáveis do óxido nítrico (NO), um importante mediador intra- e intercelular, cujo tempo de vida, nos humanos, é de escassos segundos. Como tal, para monitorizar a produção de NO, é comum proceder-se a análises clínicas dos iões $\mathrm{NO}_{3}$ e $\mathrm{NO}_{2}^{-}$em fluidos biológicos, tais como a urina e o plasma [5-7].

Pelas razões expostas, a determinação analítica dos nitratos e nitritos em amostras de origem ambiental, clínica e alimentar é, presentemente, um assunto de grande interesse [4,5]. São conhecidas numerosas técnicas para a determinação directa de nitritos (ou indirecta de nitratos, por redução prévia a nitritos), que vão desde os ensaios colorimétricos baseados na reacção de Griess, passan- do pelos métodos polarográficos e cromatográficos, até à quimiluminescência e à electroforese capilar $[3,4]$. Todavia, muitas destas técnicas são morosas e complexas, quer ao nivel do procedimento experimental quer ao nivel da preparação da amostra. Outras desvantagens frequentemente apontadas são a falta de especificidade e/ou de sensibilidade, especialmente quando aplicadas em amostras complexas ou com conteúdo analítico muito baixo [3]. Consequentemente, é essêncial encontrar um método analítico que reúna em simultâneo alguns aspectos chave, como a sensibilidade, a especificidade, a rapidez e a simplicidade. Neste contexto, a tecnologia das enzimas imobilizadas surge como uma opção muito atraente para o desenvolvimento de um biosensor capaz de responder às exigências acima mencionadas, especialmente no que concerne à selectividade [8-10]. A figura $1 \mathrm{~A}$ descreve resumidamente a constituição de um biosensor.

\footnotetext{
* Departamento de Química, Centro de Química Fina e Biotecnologia, REQUIMTE, Faculdade de Ciências e Tecnologia, Universidade Nova de Lisboa, 2825-114 Monte de Caparica, Portugal
} 